\title{
The Effect of Spiritual Practice allong with Routime Medical Care on the Recovery of Patients Hospitalized with Covid-19: a Randomized Clinical Trial
}

\section{ART ICLE INF O}

\section{Article Type}

Original Research

\section{Authors}

Jahangir A. ${ }^{1} M S C$

Mousavi B. ${ }^{* 2} M D, M P H$

Asgari M. ${ }^{3} M S C$,

Mahdavi R. ${ }^{3} B S C$

Karbakhsh M. ${ }^{4} M D$

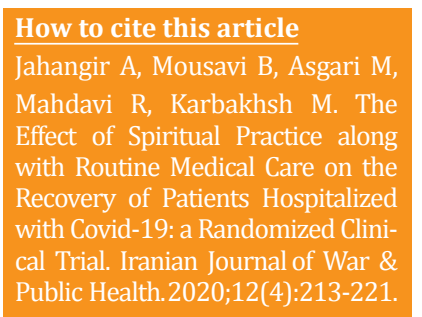

${ }^{1}$ Retired Lecturer, School of Nursing and Midwifery, Army University of Medical Sciences

${ }^{2}$ Prevention Department, Specialist in community and preventive medicine, Janbazan Medical and Engineering Research Center (JMERC), Tehran, Iran

${ }^{3}$ Janbazan Medical and Engineering Research Center (JMERC), Tehran Iran

${ }^{4}$ Professor, Community Health Department, Tehran University of Medica Sciences

\section{Correspondence*}

Address: Janbazan Medical and Engineering Research Center (JMERC), Tehran, Iran

Phone: +98 (21) 22416699

Fax: +98(21) 22412114

mousavi.b@gmail.com

\section{Article History}

Received: October 28, 2020

Accepted: November 30, 2020

ePublished: March 09, 2021

\section{A B S T R A C T}

Aims This study was conducted to determine the effects of spiritual practice along routine medical care on the recovery of patients admitted with Covid-19.

Materials \& Methods In a single-blinded clinical trial study 64 hospitalized patients with Covid-19, were randomly assigned in to two groups of intervention (spiritual practice+ routine treatment) and comparison (routine treatment). The intervention was performed using religious teachings, spiritual practice was taught to the patients in the intervention group with the intention of recovery and comfort. Spiritual practice was reciting Surah "AlHamd" and "Ya-Allah". The intervention group accomplished spiritual practice three times a day (21 times in total) for 7 days. Information gathered on demographic characteristics, depression and anxiety score, length of hospital stay, ICU transfer, intubation, and patient death. The Hospital Anxiety and Depression Scale (HADS) questionnaire was used to determine the symptoms of depression and anxiety.

Findings A total of 35 participants in the comparison group and 29 in the intervention group completed the study. After intervention, there was no significant difference between the length of hospitalization days between the intervention group (5.8 \pm 1.7$)$ and the comparison $(6.7 \pm 1.7)$. The rate of ICU request was significantly higher in the comparison group $(40 \%, n=14)$ than in the intervention group $(3.4 \%, n=1)(P<0.001)$. In the intervention group, no cases of intubation and death occurred, in the comparison group, these rates were $40 \%(n=14)$ and $45.7 \%(n=16)$, respectively, and the difference was significant $(P<0.001)$. The mean difference of anxiety score before and after spiritual practice in the intervention group was $3.1( \pm 3.6)$ and the comparison was $0.9( \pm 2.6)(P=0.03)$. The mean difference of depression in the intervention group was 1.5 (2.1) and the comparison was $0.9(1.8)(\mathrm{P}$ $<0.001$ ).

Conclusion Spiritual practice along with routine medical care, can lead to less mortality/ ICU transmission/intubation, improved anxiety/depression, as well as, improved recovery among Covid-19 hospitalized patients.

Keywords Spiritual; Anxiety; Depression; Covid-19

\section{I T A T I O N L I N KS}

[1] World health organization ... [2] Severe acute respiratory ... [3] COVID-19: What is next ... [4] Coronavirus disease ... [5] Clinical characteristics ... [6] Pathophysiology, Transmission ... [7] Overview of the 2019 ... [8] Clinical trials on drug ... [9] Novel Coronavirus disease 2019 ... [10] Report of the world ... [11] The many methods ... [12] Religion, spirituality, and ... [13] Effects of spiritual ... [14] Spiritual care ... [15] Spiritual medicine in the ... [16] Traditional and ... [17] Evidence map ... [18] Exploring alternative medicine ... [19] Spiritual care-'A deeper ... [20] ChurchInAction: the role of ... [21] The role of spirituality in the ... [22] WHO global report ... [23] Investigating the auditory effects ... [24] Interpretation of verse ... [25] Prayer therapy (recitation ... [26] Prayer therapy ... [27] comparative study of the ... [28] The hospital anxiety and ... [29] Religious Care Patients ... [30] Effects of intercessory ... [31] The role of prayer ... [32] Effect of Quran ... [33] Religious communities ... [34] Religiosity/spirituality ... [35] Cross-national analysis ... [36] Association between ... [37] Religious service attendance... [38] Positive therapeutic ... [39] Study of the therapeutic effects ... [40] Are there demonstrable effects ... [41] Intercessory prayer ... [42] Effects of remote, retroactive ... [43] Research on religion, spirituality ... [44] Prospective prediction of suicide ... [45] Religious service attendance ... [46] Association between religious service ... [47] A randomized trial of the ... [48] Intercessory prayer in ... [49] Private prayer associations ... [50] Effectiveness of prayer in ... [51] Mindfulness, spirituality, and ... [52] The effect of prayer on mental ... 


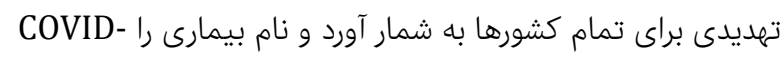

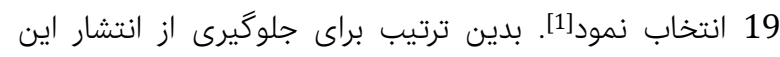

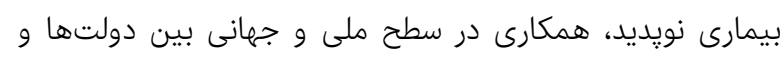

عموم مردم را ضرورى دانست[2].

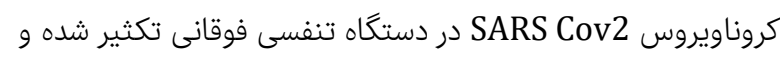

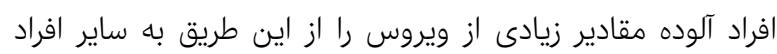

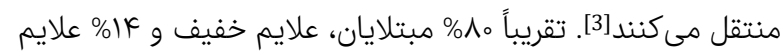

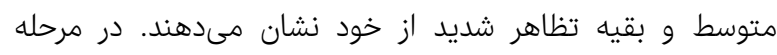
مقدماتى، بيمارى مىتواند با علايم غيراختصاصى مانند احساس

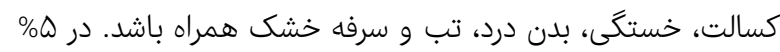

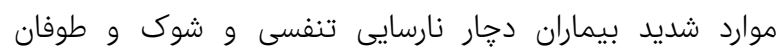

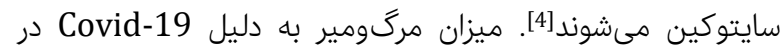

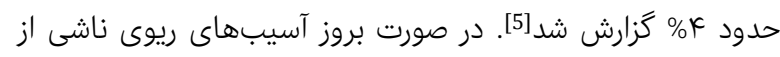

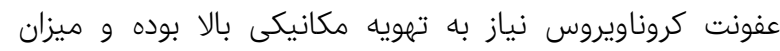

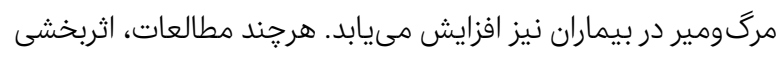

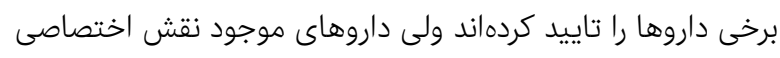

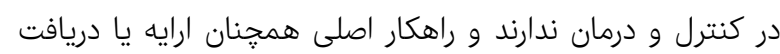

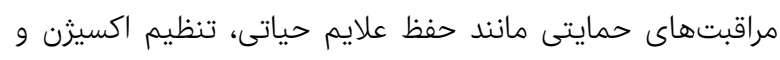
فشار خون و كاهش عوارض ايجاد شده (مانند عفونتهاي ثانيان ثانويه يانيا

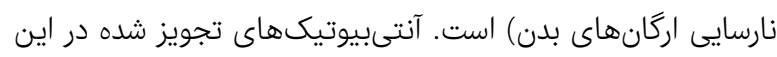

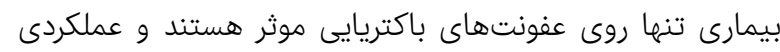

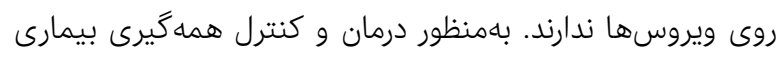

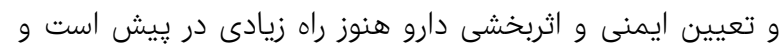

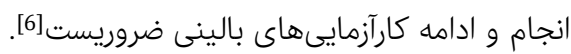

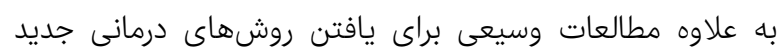
مقابله و كشف واكسن با اين ويروس در دنيا در حال دان انجام است.

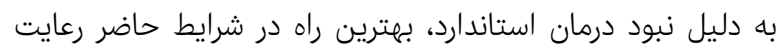

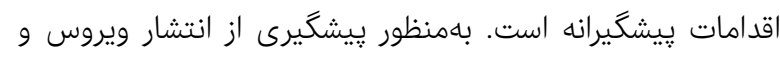

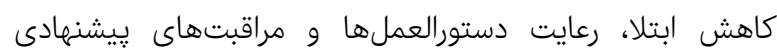

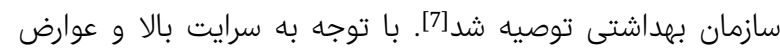

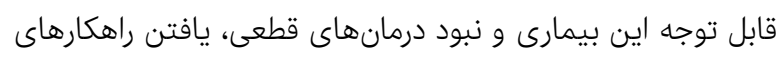

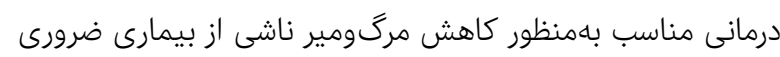
به نظر مىرسد

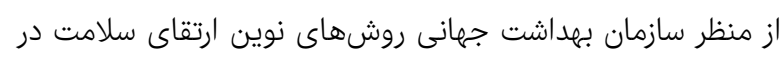

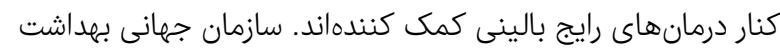

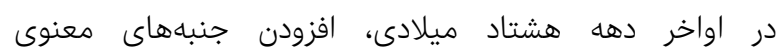

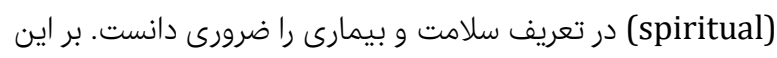

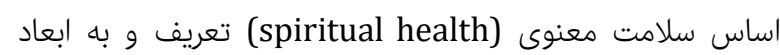
جسمى، روانى و اجتماعى سلامت اضافه شد و كشورها متعهد شدند

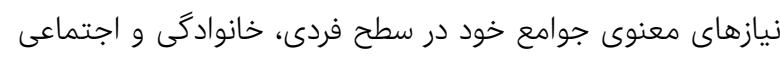

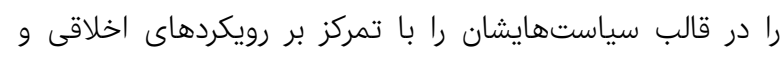

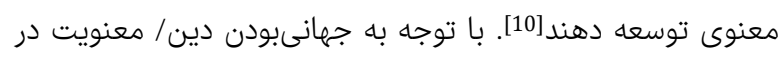

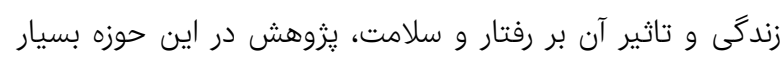
مهم و ارزشمند است. عواملى جون ارزيابى مجدد و تعريف فرد از
تاثير افزودن مراقبت معنوى به درمانهاى معمول بر روند بهبودى بيماران بسترى مبتلا به كوويد-19: كارآزمايى بالينى تصادفى

\section{اكرم جهانكير MSc}

مدرس بازنشسته يُرستارى و مامايى، دانشكاه علوم يزشكى ارتش، تهران، ايران

بتول موسوى "

متخصص طب بيشكَيرى و يزشكى اجتماعى، كروه بيشكَيرى، مركز تحقيقات

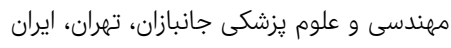

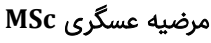

مركز تحقيقات مهندسى و علوم بزّشكى جانبازان، تهران، ايران

BSc راحله مهدوى تحفيتات ميندسي

مركز تحقيقات مهيندسى و علوم يُزشكى جانبازان، تهران، ايران

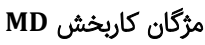

استاد يُشكى اجتماعى، دانشكده بِزشكى، دانشكاه علوم بِزشكى تهران، ايران

جكيده

اهداف: هدف اين يزووهش افزودن مراقبت معنوى به درمانهاى معمول و تعييين

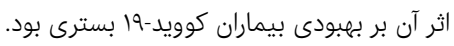

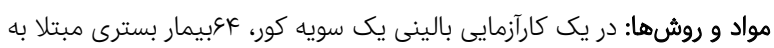

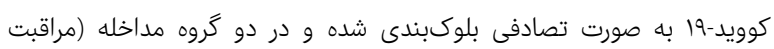

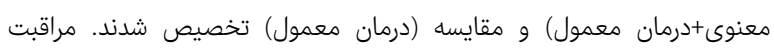

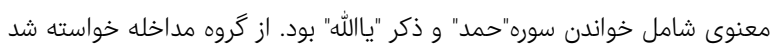

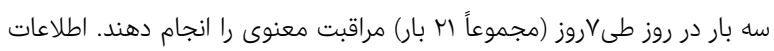

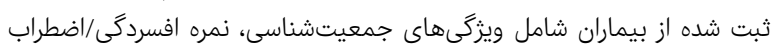
بيمارستانى (با استفاده از - Hospital Anxiety and Depression Scale

يالئه:)، درADS

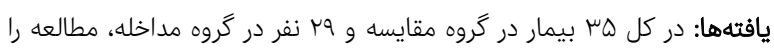

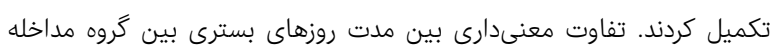

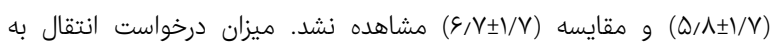

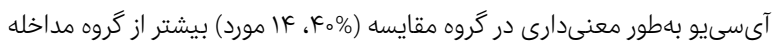

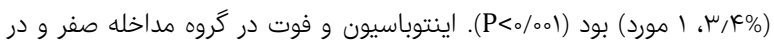

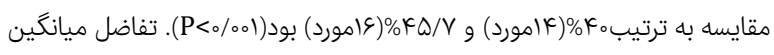

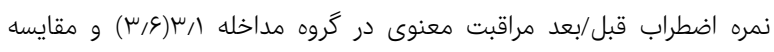

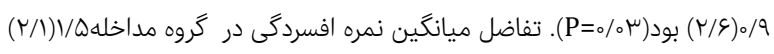

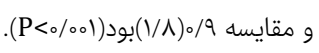

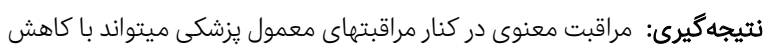

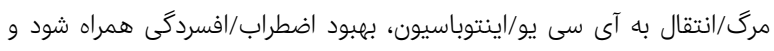

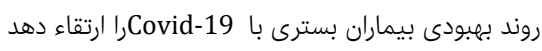

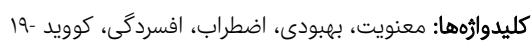

تاريخ دريافت: تاريخ يذرش:

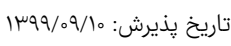

mousavi.b@gmail.com :نويسنده مسئول: لنايرش:

\section{مقدمه - مقد}

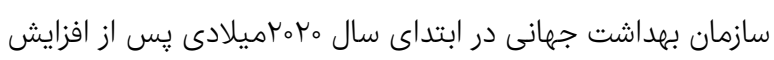

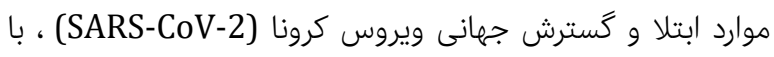

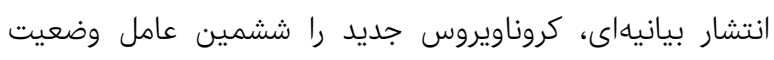

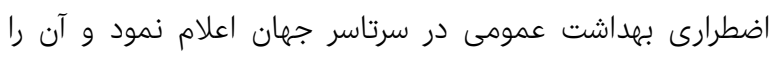




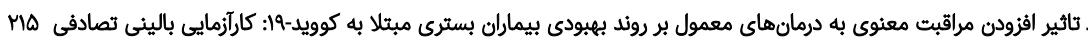

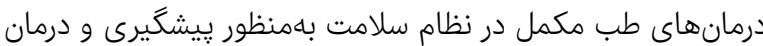

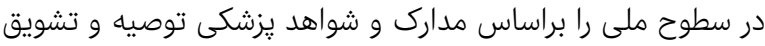

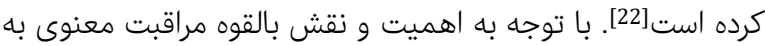

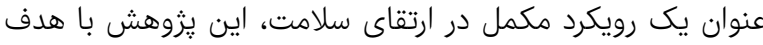
تعيين اثربخشى مراقبت معنوى (Spiritual practice) بر روند بهبودى بيماران بسترى مبتلا به كوويد-19 انجام شد.

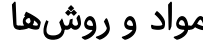

در اين كارآزمايى بالينى تصادفى شاهددار يك سويه كور، تاثير

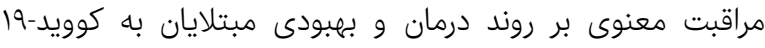
بسترى در بيمارستان امام حسين در تيرماه وهسا ارزيابى شد. معيار

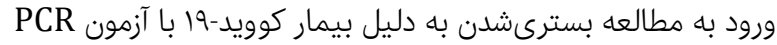

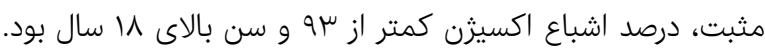
بيماران بسترى در آى سى يو، مادران باردار، وجود اختلالات شناخت آنته

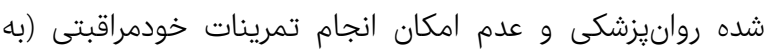

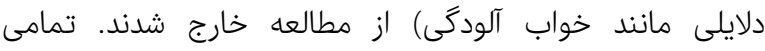

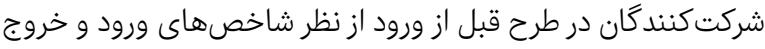

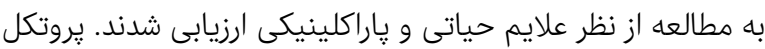

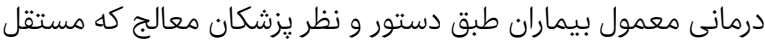
از تيم يزوهش بودند ادامه داشت. به دليل نبودن مطالعه مشابه در مراقبت معنوى و كرونا از حجم المراني

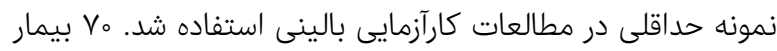

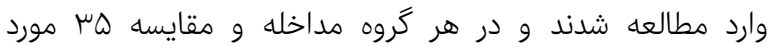

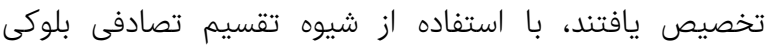

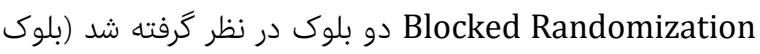

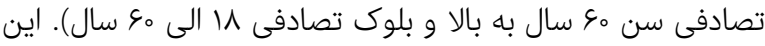

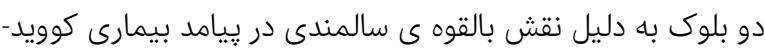

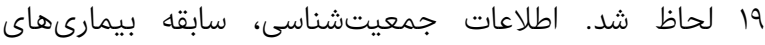
زمينهاى/عوامل خطر و نمايه توده بدنى در ابتداى ورود به مطالعه

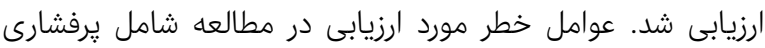

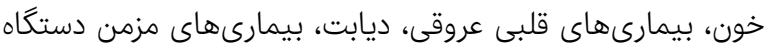

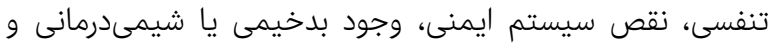

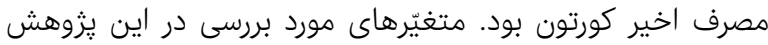
براى مقايسه ى دو گروه شامل نماى تشخيصى در سيى تى تى اسكن

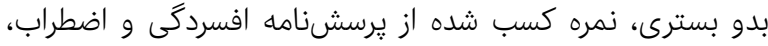

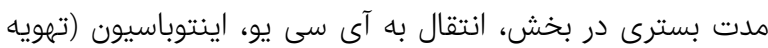

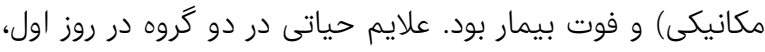

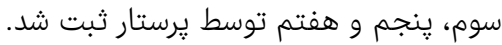

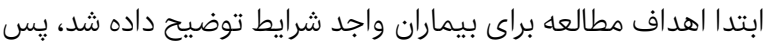

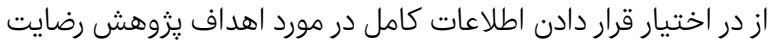

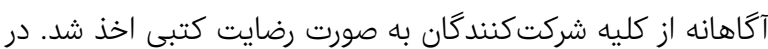

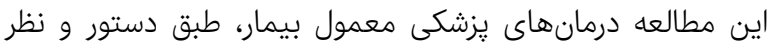

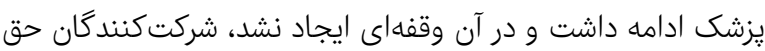

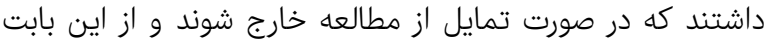

معنويت، بخشش/تصفيه مذهبى و علاقه به دريافت حمايت مذهبى

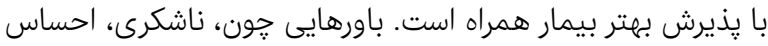

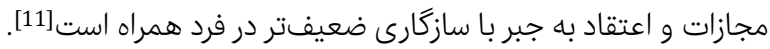

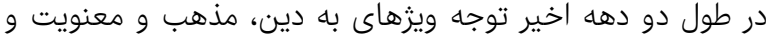
تاثير آن بر حفظ و ارتقاى سلامت و بهائ دخصوص روند درمان شده

از آنجا كه رفتار معنوى از باور دينى در فرد شكل مى ميَيرد،

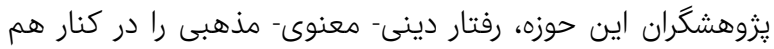

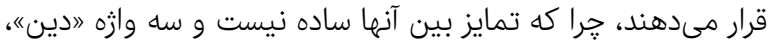

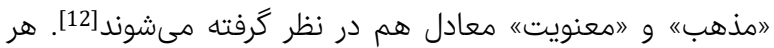
קند نقش معنويت در ارتقاى سلامت از نكاه يُوهششكران موافقين

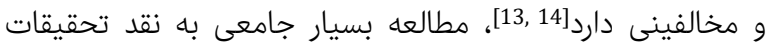

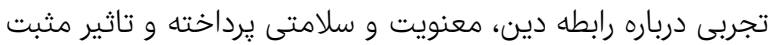

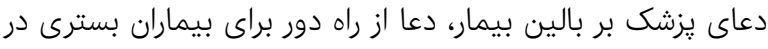

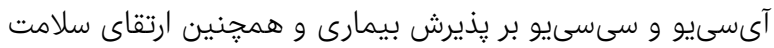

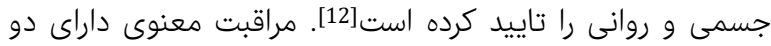

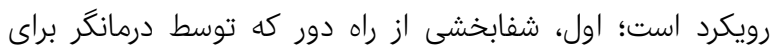

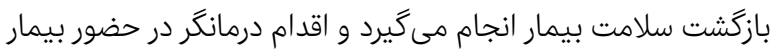

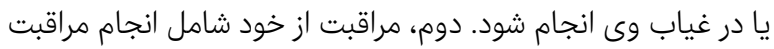

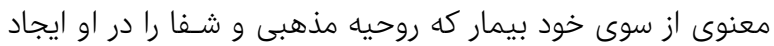
كند مثلاً خواندن ذكر يا آيات خاصى از قرآن [15]. قرآن كريم در آيات آنات

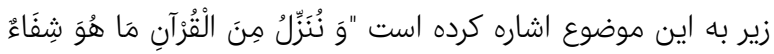

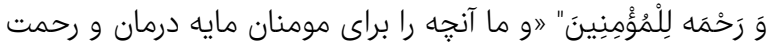
است از قرآن نازل مىكنيمه (سوره اسرا- آيه به) و "أَلاَ به ذكر اللّه

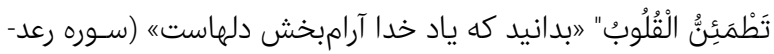

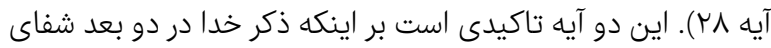
جسمى و شفاى روحى داراى اثر است. ياد خدا دلها را آرام، قلبها آنها

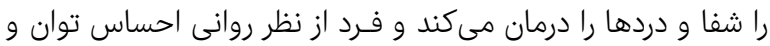
نيروى بيشترى كرده تا از مشكلات و بلايا نهراسد. بيمارى ويروس كرونا اخير به دليل عدم وجود هركَّنه درمان اثبات

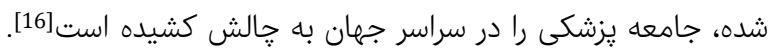

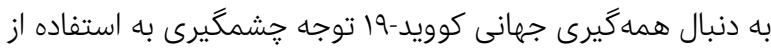

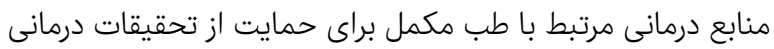

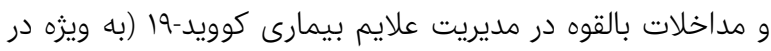

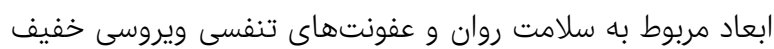

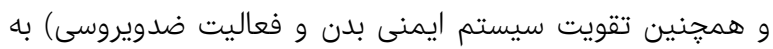

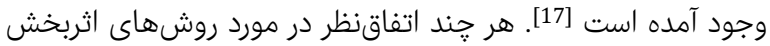

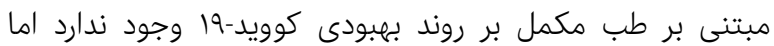

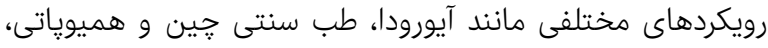
مراقبت معنوى و مذهبى با تكيه بر آموزههاى دينى در در بردئ

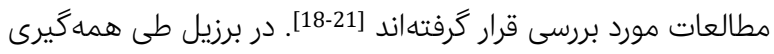

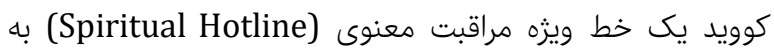
صورت يك خط تلفن رايكان براى حمايت معنوى از بيماران طراحى لئ

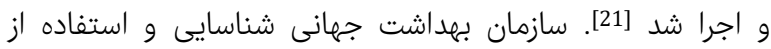


خرده مقياس افسردگى يرسشنامه HADS روى ارزيابى فقدان

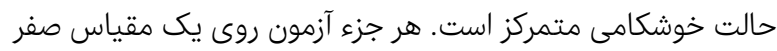

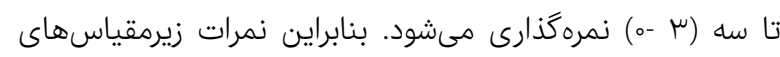

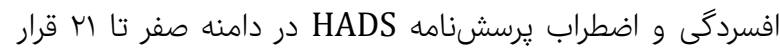

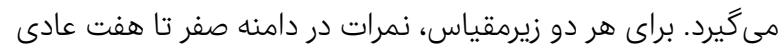

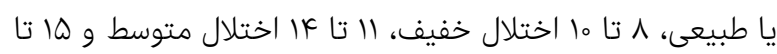

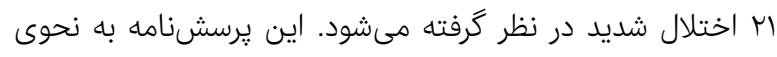

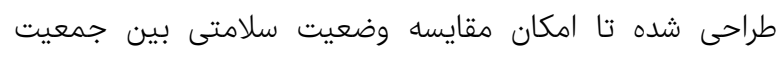

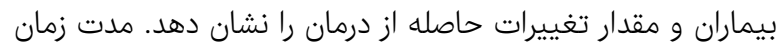

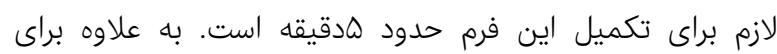

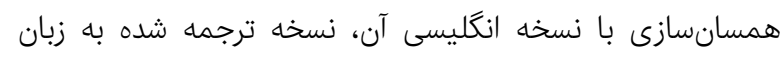

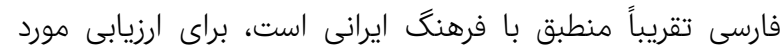
استفاده قرار كرفت[ [28].

اين تروهش با شناسه اخلاق

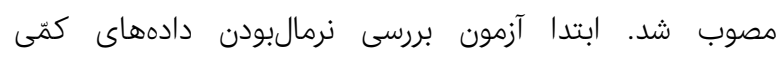

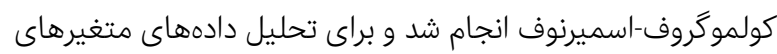

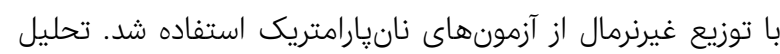

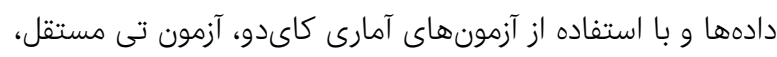

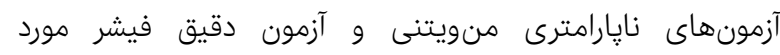

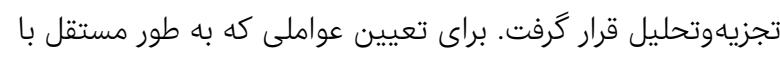

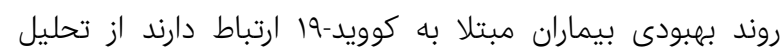

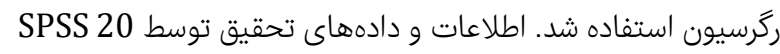

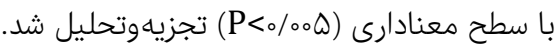

\section{يافتهها}

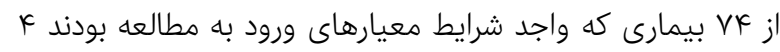

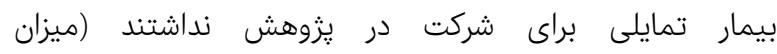

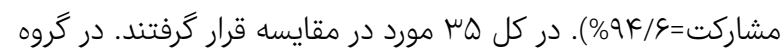

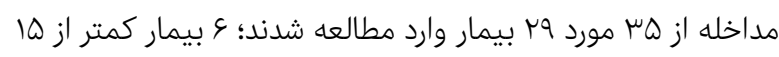

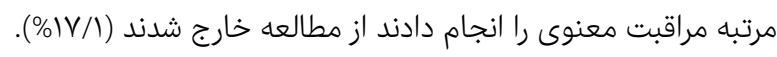

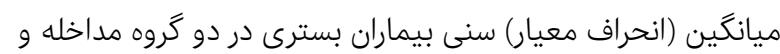

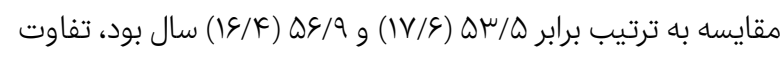

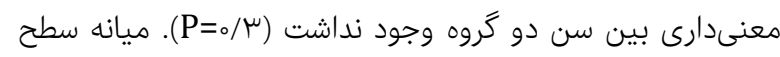

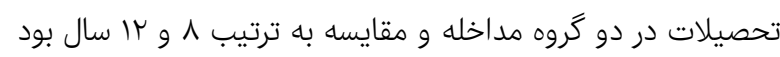

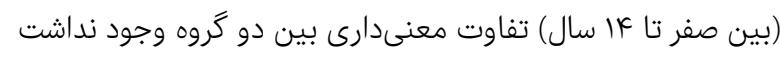

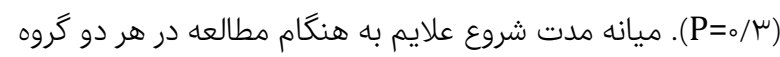

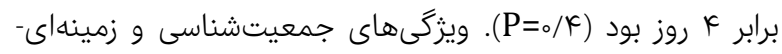

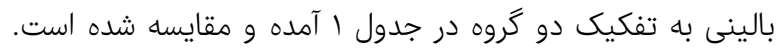

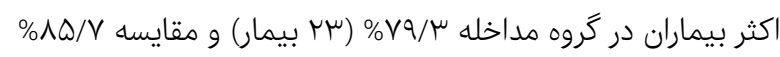

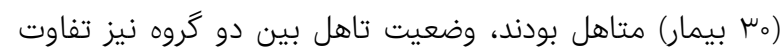

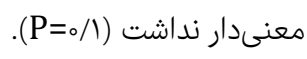

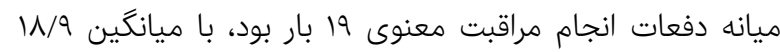

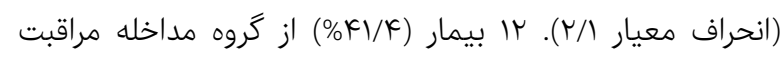

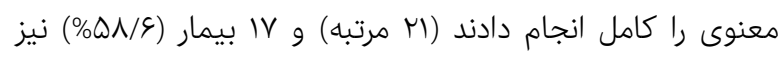

اطمينان داده شد كه در دريافت خدمات يزشكى مورد نياز

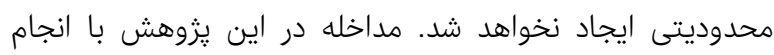

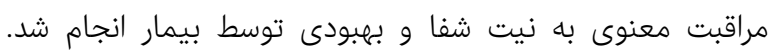

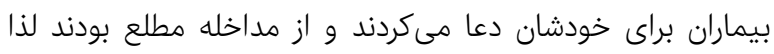

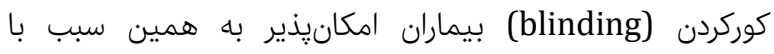

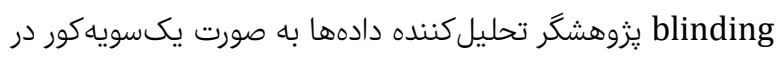

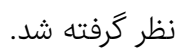

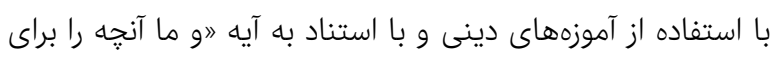

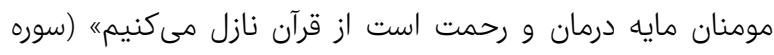

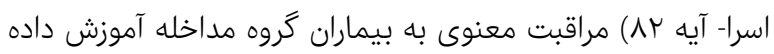

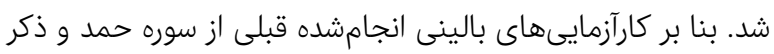

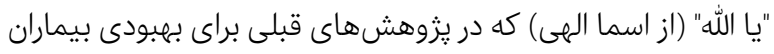

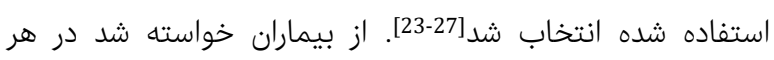

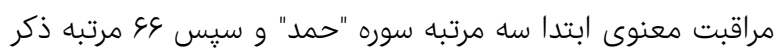

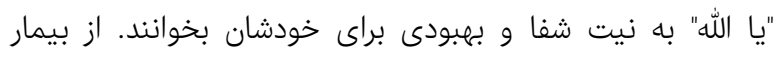

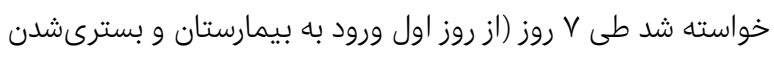

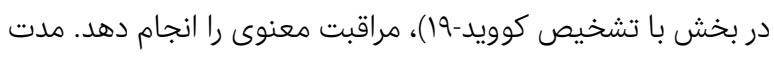

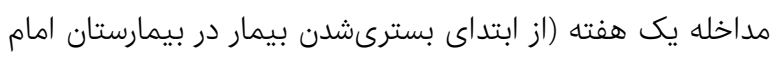

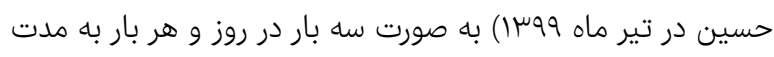

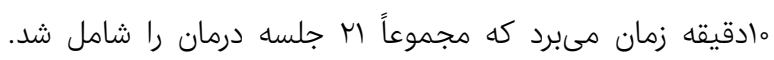

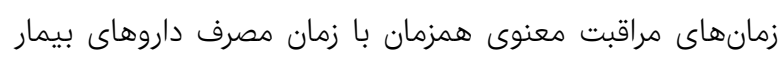

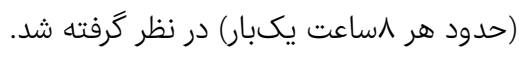

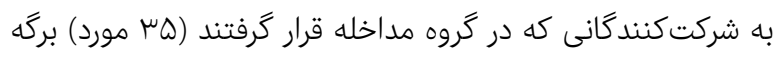

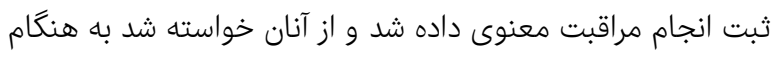

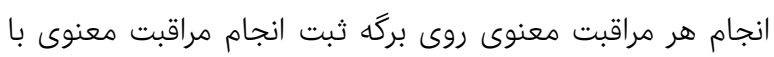

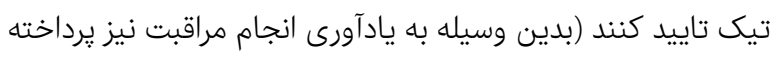

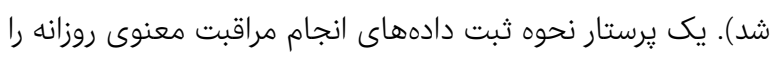

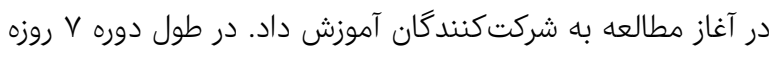

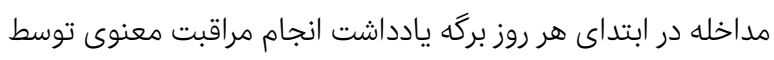

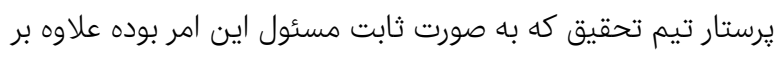

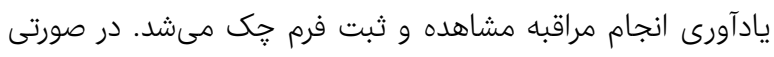

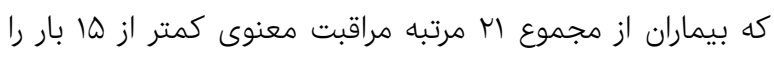

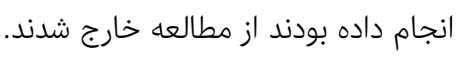

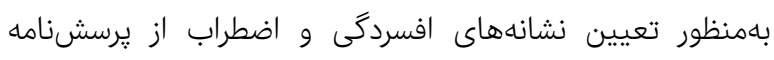

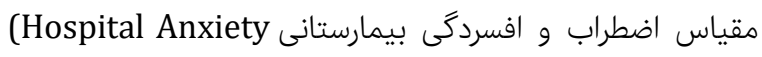
and Depression Scale- HADS)

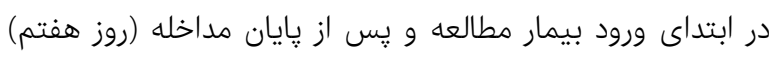
تكميل شد. برسشنامه HADS يكى ابزار غربالكرى براى ارزيابى اضطراب و و

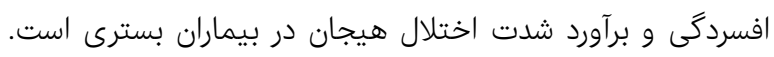

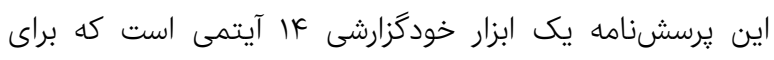

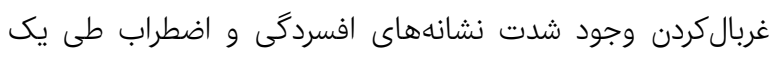

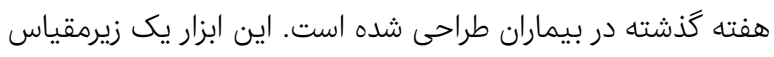

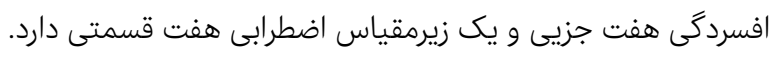




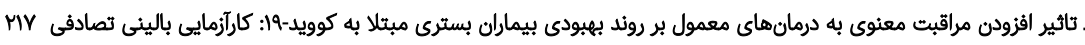

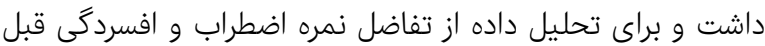

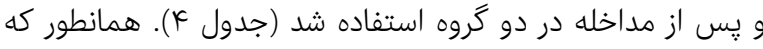

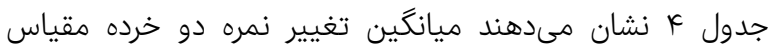

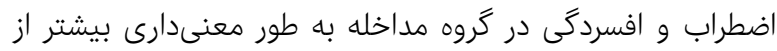

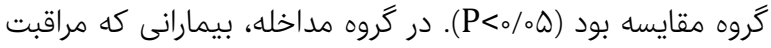

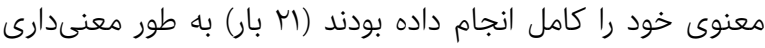

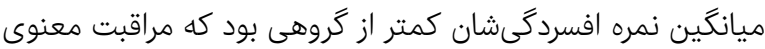

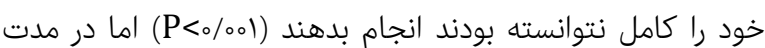

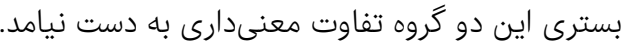

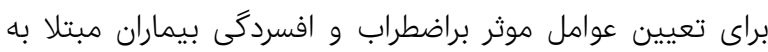

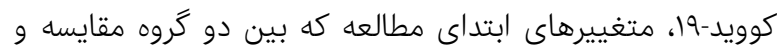

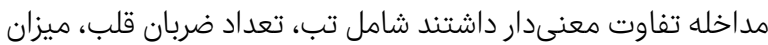

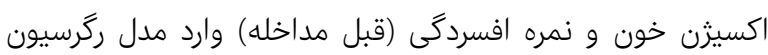

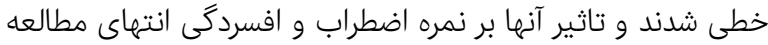

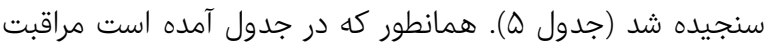
معنوى تاثير معنادارى بر نمره ى نهايى هر دو دمان خرده مقياس

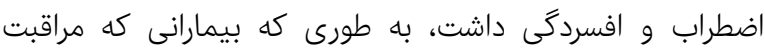

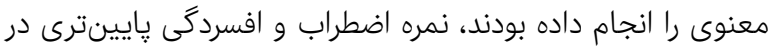

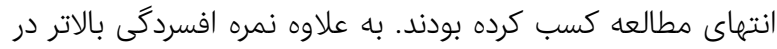

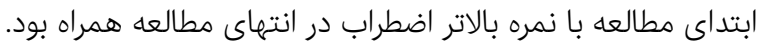

حداقل يك بار انجام مراقبت معنوى را فراموش كرده بودند. براى

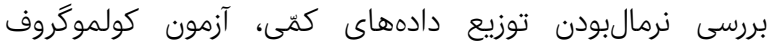
اسميرنوف انجام شد و مشخص شد كه براى متغيّرهاى نمايه توده

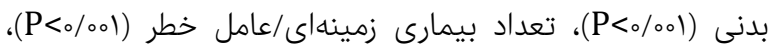

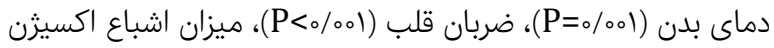
(P<o/.01) متغيّرهاى سن، مدت بسترى، اضطراب و افسردگى تابع توزيع نرمال

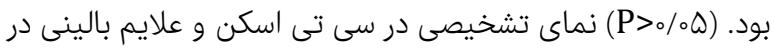

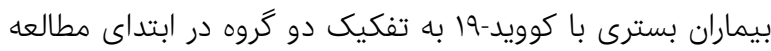
در جدول r با هم مقايسه شده است. در ابتداى مطالعه ميانكين

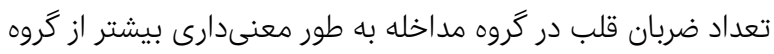

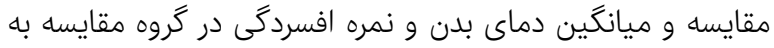

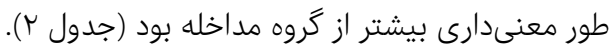

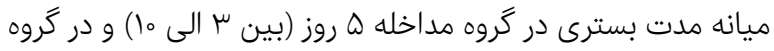

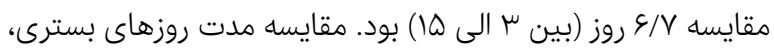

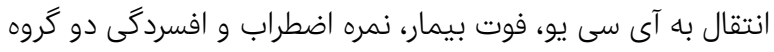

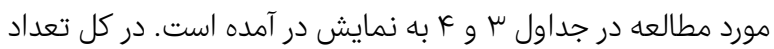

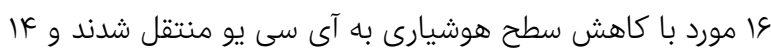

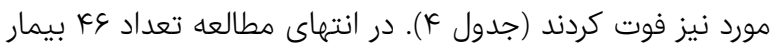
داراى سطح هوشيارى مناسب بودند و يرسشنامه

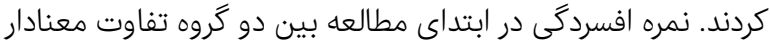

جدول () ويثگگهاى زمينهاي، جمعيتشناختى و بالينى در بيماران بسترى با كوويد-19 به تفكيك دو گروه در ابتداى مطالعه

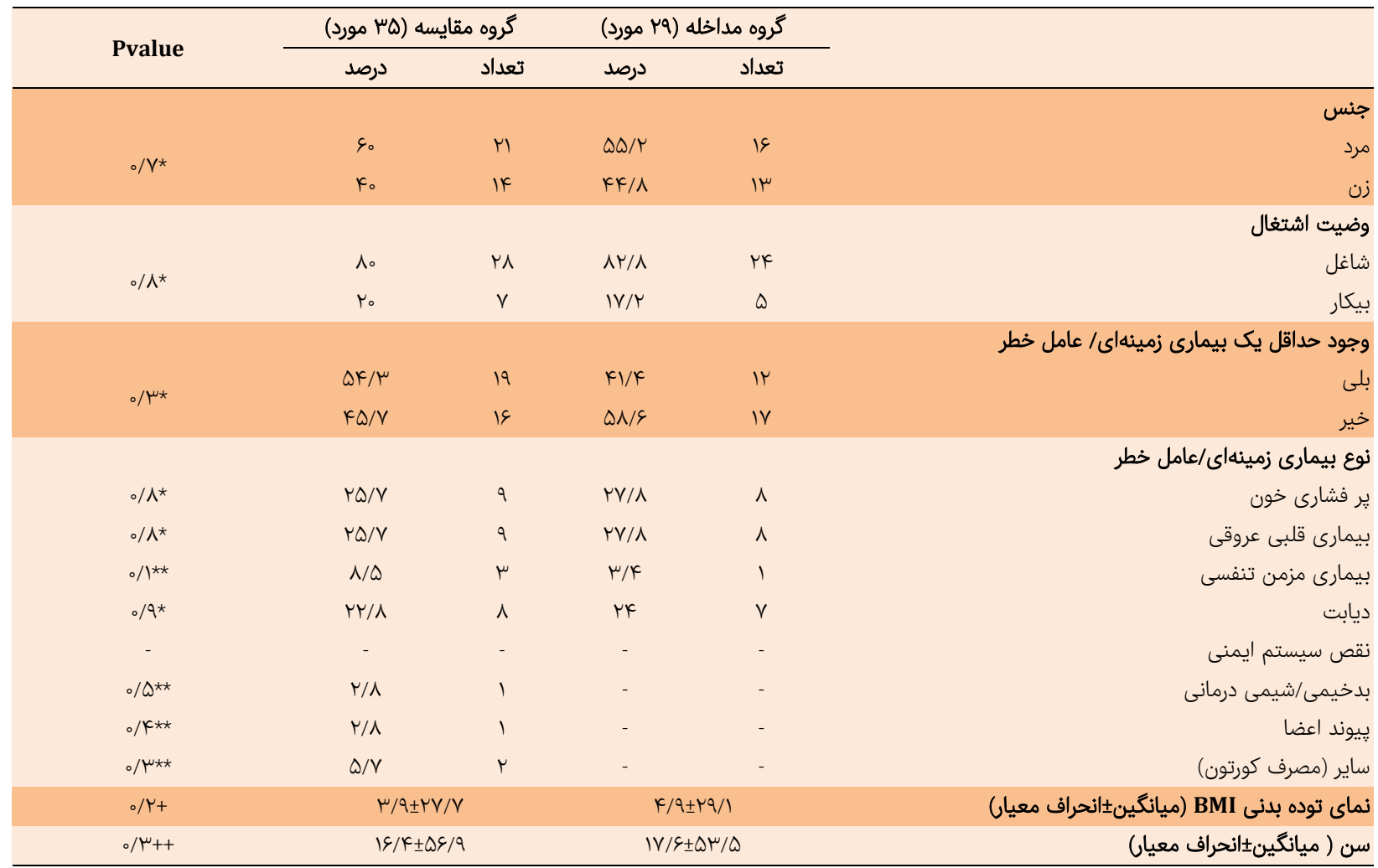

${ }^{*}$ chi-square test, ${ }^{* *}$ fisher exact-test, + mann-whitney test, ++ independent t-test 


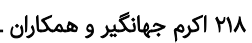

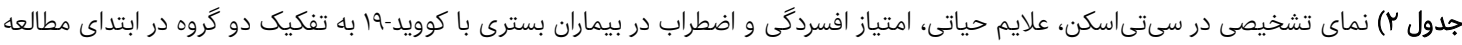

\begin{tabular}{|c|c|c|c|c|c|}
\hline \multirow{2}{*}{ p-value } & \multicolumn{2}{|c|}{ كروه مقايسه (ه广 مورد) } & \multicolumn{2}{|c|}{ گروه مداخله (Mq مورد) } & \multirow{2}{*}{ 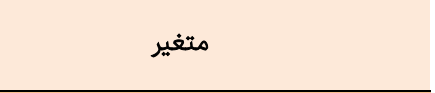 } \\
\hline & ميانگين & تعداد (درصد) & ميانكين & تعداد (درصد) & \\
\hline \multirow{4}{*}{$*_{\circ} / r$} & & & & & نماى تشخيصى سىىىاسكن هنكام بسترى \\
\hline & 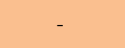 & $M\left(\varepsilon_{0}\right)$ & - & $M(\varepsilon r / M)$ & Ground Glass \\
\hline & - & $10(K N / 9)$ & - & $k(I K / \Lambda)$ & Patchy Infiltration \\
\hline & - & $F(I I / F)$ & - & $V(Y K / I)$ & Consolidation \\
\hline & & & & & علايم حياتى هنكام بسترى \\
\hline$* * \circ / \circ 1$ & $\mu \Lambda / I \pm \circ / V$ & - & $\mu V / \varsigma_{ \pm 0} / V$ & - & دماى بدن ( ) \\
\hline$* * / V$ & $1 Q / \mu \pm r / r$ & - & $1 Q / K \pm r / \&$ & - & تعداد تنفس در دقيقه \\
\hline$* * \circ \uparrow$ & $q_{0} / k \pm 9 / 9$ & - & $9 k / k \pm 10 / 8$ & - & تعداد ضربان قلب در دقيقه \\
\hline$* * \circ \% 9$ & $\Lambda N / \mathcal{F}_{ \pm}+\Lambda / \Lambda$ & - & $\wedge 9 / \wedge \pm 1 / \vee$ & - & $\mathrm{SPO} 2$ \\
\hline & & & & & برسشنامه HADS \\
\hline$+0 / 4$ & $V / q \pm F / 。$ & - & $\Lambda / K \pm F / \varepsilon$ & - & 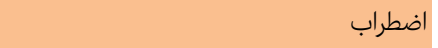 \\
\hline$+\circ / \% \mu$ & $\varepsilon / \mathrm{V} \pm \mu / \mathrm{V}$ & - & $r / q \pm r / \Lambda$ & - & افسردگى \\
\hline
\end{tabular}

${ }^{*}$ chi-square test, ${ }^{* *}$ mann-whitney test, +independent t-test

جدول سا) مقايسه مدت روزهاى بسترى و انتقال به آىسىيو بعد از انجام مداخله در دو گروه مورد مطالعه

\begin{tabular}{|c|c|c|c|}
\hline p-value & كروه مقايسه & 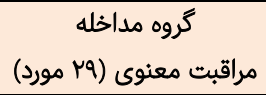 & \\
\hline & تعداد & تعداد & \\
\hline$*_{\circ / \gamma}$ & $(1 / V) s / V$ & $(\mathrm{I} / \mathrm{V}) \mathrm{Q} / \Lambda$ & روزهاى بسترى ميانكين (انحراف معيار) \\
\hline$* * / \%$ & if & 1 & درخواست انتقال به آىسىيو \\
\hline$* *_{\circ} / \mathbb{A}$ & r & 。 & انتقال به آىسىيو \\
\hline$* *_{\circ} / 000$ & ik & 。 & اينتوبه شده \\
\hline$* *_{\circ} / 000$ & 18 & 。 & فوت \\
\hline
\end{tabular}

*independent t-test, ${ }^{* *}$ fisher exact-test

جدول F) مقايسه امتياز اضطراب و افسردگى در دو گروه مورد مطالعه

\begin{tabular}{|c|c|c|c|c|c|c|c|c|c|c|c|c|c|}
\hline \multirow{3}{*}{$\begin{array}{c}\text { p- } \\
\text { value }\end{array}$} & \multicolumn{6}{|c|}{ گروه مقايسه (هس مورد) } & \multicolumn{6}{|c|}{ كروه مداخله (qr مورد) } & \\
\hline & \multicolumn{2}{|c|}{ تفاضل قبل و بعد (IN)* } & \multicolumn{2}{|c|}{ بعد از مداخله (IA)* } & \multicolumn{2}{|c|}{ 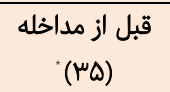 } & \multicolumn{2}{|c|}{ تفاضل قبل و بعد (rA)* } & \multicolumn{2}{|c|}{ 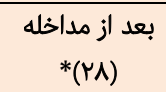 } & \multicolumn{2}{|c|}{ 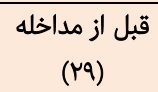 } & \\
\hline & SD & ميانكين & SD & ميانكين & SD & ميانكين & SD & ميانكين & SD & ميانكين & SD & ميانكين & \\
\hline 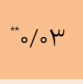 & $r / 8$ & o/9k & $\mu / \varepsilon$ & $\Lambda / \Delta$ & $k \%$ & $V / q$ & $\mu / \varepsilon$ & $\mu / \Lambda$ & $\mu / \tau$ & $\Delta / 1$ & $F / 4$ & $\Lambda / \mathcal{A}$ & اضطراب \\
\hline$" \%$ & $1 / \Lambda$ & $-0 / \wedge 9$ & س & $8 / 1$ & $\mu / \nu$ & s/V & $r / 1$ & $1 / \Delta$ & $\mu \%$ & $\mu / \mathcal{k}$ & $r / \Lambda$ & $k / q$ & $\begin{array}{l}\text { افسردگى) } \\
\text { (HADS) }\end{array}$ \\
\hline
\end{tabular}

independent t-test"

جدول ه) عوامل مرتبط با اضطراب و افسردگى در بيماران بسترى مبتلا به كوويد-19

\begin{tabular}{|c|c|c|c|}
\hline Pvalue & ضرايب استاندارد شده بتا & متغير مستقل & متغير وابسته \\
\hline$\% \mu$ & $-0 / \mu r$ & كروه مداخله & \multirow{5}{*}{ نمره اضطراب در انتهاى مطالعه } \\
\hline$\circ / \mathrm{VV}$ & $\% k$ & تب به سانتى گراد & \\
\hline$\circ / T_{0}$ & $-0 / 19$ & تعداد ضربان قلب در دقيقه & \\
\hline o/^F & $-\circ /{ }^{\mu}$ & SPO2 & \\
\hline$\circ \% \vee V$ & o/kr & نمره افسردگى قبل از مداخله & \\
\hline$\% 1$ & $-\circ / \mu \wedge$ & كروه مداخله & \multirow{4}{*}{ نمره افسردگى در انتهاى مطالعه* } \\
\hline o/\&V & $-0 \%$ & تب به سانتى گراد & \\
\hline $0 / \& \Lambda$ & $\circ / 11$ & تعداد ضربان قلب در دقيقه & \\
\hline$\% \wedge$ & $-0 / \% Y$ & $\mathrm{SPO} 2$ & \\
\hline
\end{tabular}




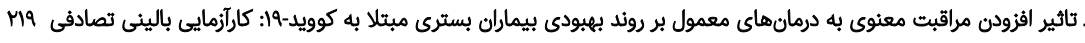

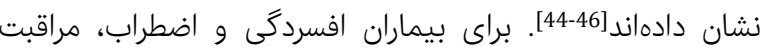
معنوى ممكن است به عنوان روش كمكى در كنار مراقبتهاى بـاي

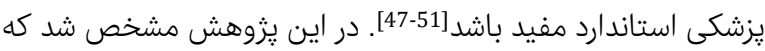

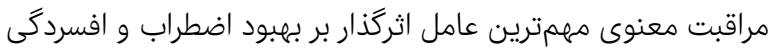

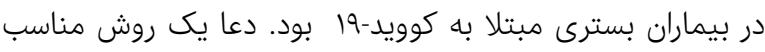

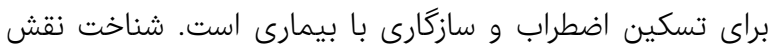

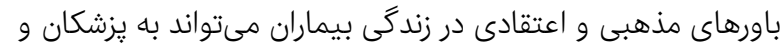

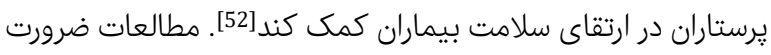

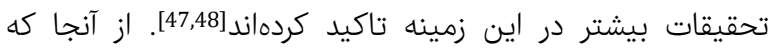

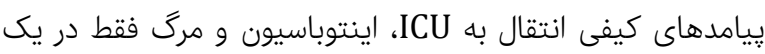

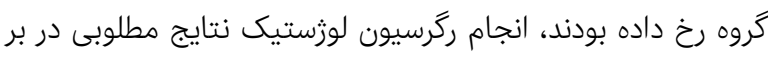

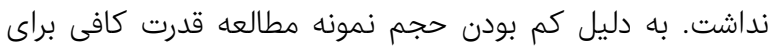

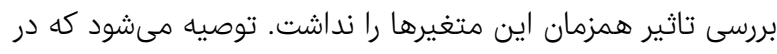

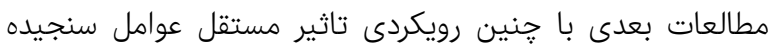

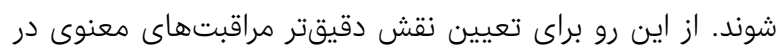

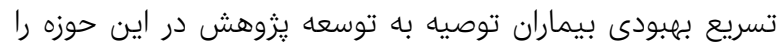

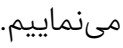

\section{نتيجه}

ميل به دعا و نيايش امرى فطرى است و يك نياز اساسى در بشر

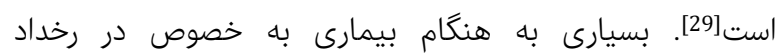
بيمارىهاى تهديد كننده ى حيات دعا مىخوانند[30]. با توجه به به به بهاريه

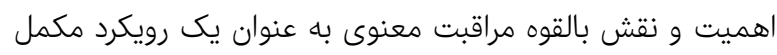
در ارتقاى سلامت، اثربخشى مراقبت معنوى بر روند بهبودى بيماران

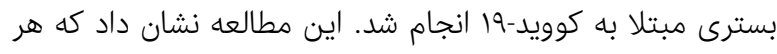

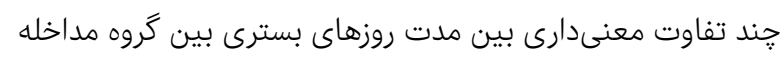

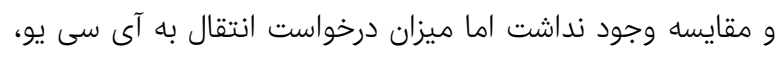

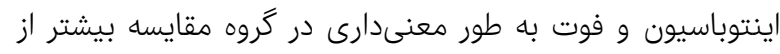

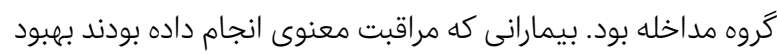

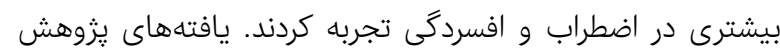
نشان داد كه مراقبت معنوى موجب كاهش ميزان فوت، إنتر انتقال به

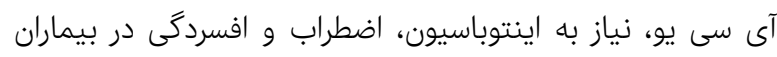

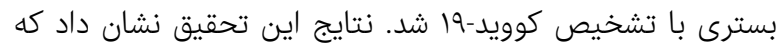

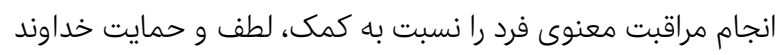

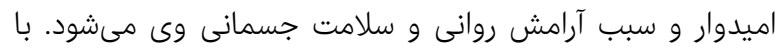

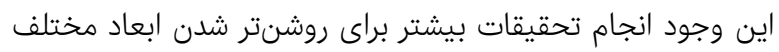
توصيه مىشود. انجام آزمايشات دوسوكور به دليل اين روش درد درمان

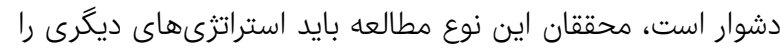

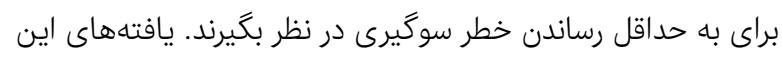

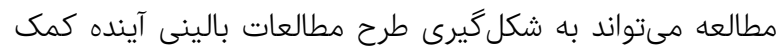

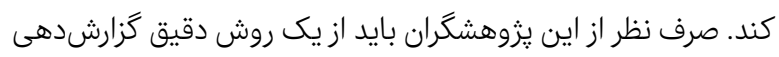

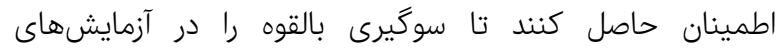
ارزيابى اثربخشى مراقبت معنوى براى درمان COVID-19 كاهش اهن بان

اين مطالعه نشان داد كه انجام مراقبت معنوى با نيت شفا براى

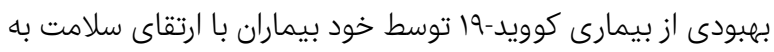

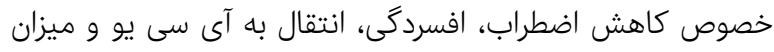

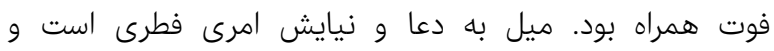
مراقبتهاى معنوى به عنوان يك نياز اساسى در بشر مطرح

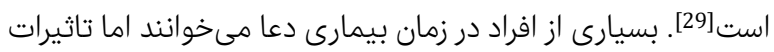

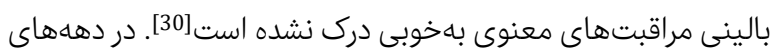

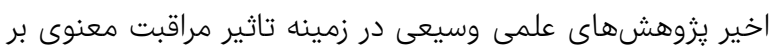

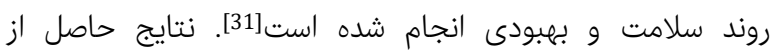

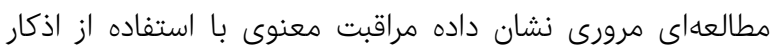
قرآنى تاثيرات مثبتى بر تقويت حافظه، سلامت روان، كاهش دران مران

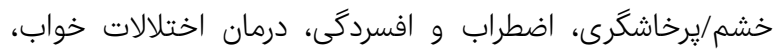

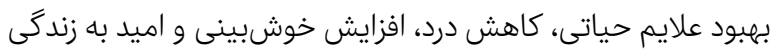
دارد[30,32]. جداى از نقش مراقئ كاهثن درد، افزيش معنوى بر سلامت، مشاركت در

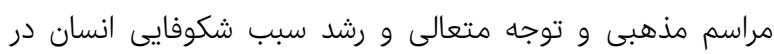

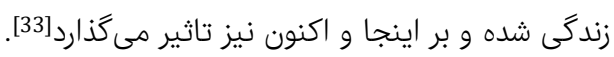

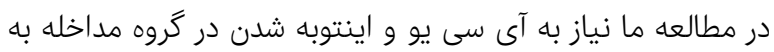

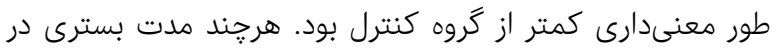

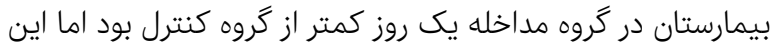

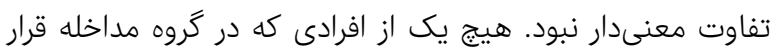

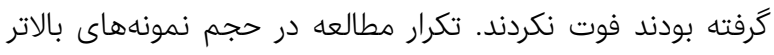
مىتواند اين تفاوتها با دقت بيشترى تاييد و نشان دهد. مطالعات

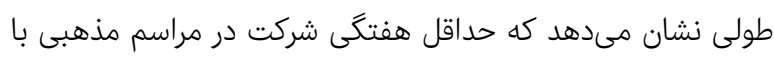

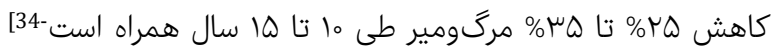

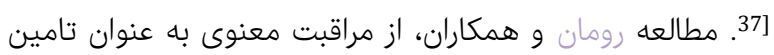

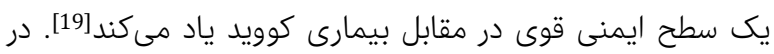

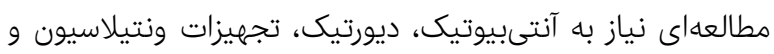
تهويه مصنوعى به مقدار و مدت كمتر گزارش شد [38]. مطالعات

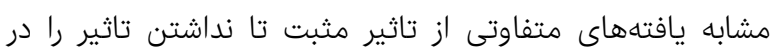

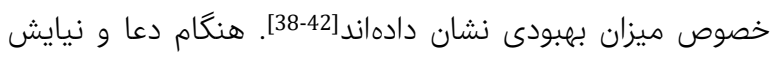

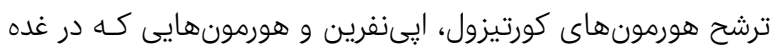

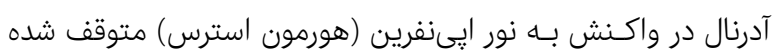

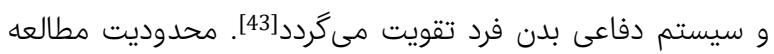

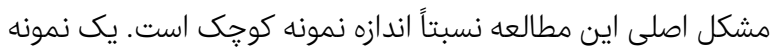
بزرگتر ممكن است قادر باشد تفاوتهاى بيشترى ييدا كند. توصييه

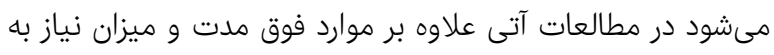

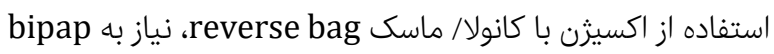

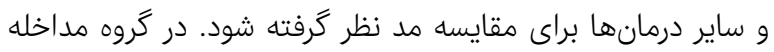

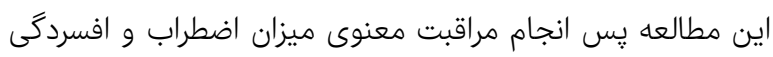

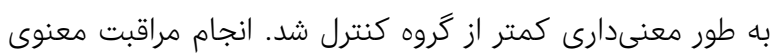

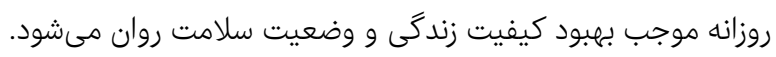

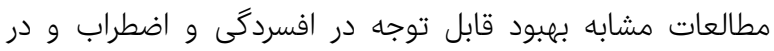

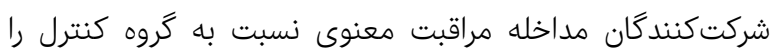


18.Nandan A, Tiwari S, Sharma V. Exploring alternative medicine options for the prevention or treatment of coronavirus disease 2019 (COVID-19)-A systematic scoping review. medRxiv. 2020 Jan 1.

19.Roman NV, Mthembu TG, Hoosen M. Spiritual care-'A deeper immunity'-A response to Covid-19 pandemic. African Journal of Primary Health Care \& Family Medicine. 2020;12(1).

20.Del Castillo FA, Biana HT, Joaquin JJ. ChurchInAction: the role of religious interventions in times of COVID-19. Journal of Public Health. 2020 Aug 18;42(3):633-4. 21.Ribeiro MR, Damiano RF, Marujo R, Nasri F, Lucchetti G. The role of spirituality in the COVID-19 pandemic: a spiritual hotline project. Journal of Public Health. 2020 Dec;42(4):855-6

22- World health organization. WHO global report on traditional and complementary medicine 2019 [Internet]. Geneva: World Health Organization; 2019 [Cited Y M D]. Available from: https://apps.who.int/iris/handle/10665/312342.

23- Forouhari S, Honarvaran R, Masumi R, Robati M, Hashemzadeh I, Setayesh Y. Investigating the auditory effects of Holy Quranic voice on labor pain. J Quran Med. 2009;1(2):18-22. [Persian]

24- Jahangir A, Maftoon F. Interpretation of verse 82 of Surah Isra regarding prayer and healing. Interdiscip Quranic Stud. 2008;1(1):39-42. [Persian]

25- Maftoon F, Jahangir A, Sedighi J, Karbakhsh Davari M, Farzadi F, Khodaei S. Prayer therapy (recitation of Surah Al-Fatihah Al-Kitab and Surah Al-Tawhid) and quality of life in patients with multiple sclerosis (MS). Interdiscip Quranic Stud. 2008;1(1):35-8. [Persian]

26- Etefagh L, Azma K, Jahangir A. Prayer therapy: application of verses of Fatiha al-Kitab and chapters of Tawhid and Qadr in patients with carpal tunnel syndrome. Interdiscip Quranic Stud. 2009;1(2):27-31. [Persian]

27- Farzin Ara F, Zare M, Mousavi Garmaroudi SM, Behnam Vashani HR, Talebi S. comparative study of the effect of Allah's recitation and rhythmic breathing on postoperative pain in orthopedic patients. J Anesthesiol Pain. 2018;9(1):68-78. [Persian]

28- Montazeri A, Vahdaninia M, Ebrahimi M, Jarvandi S. The hospital anxiety and depression scale (HADS): Translation and valid study of the Iranian version. Health Qual Life Outcomes. 2003;1:14.

29- Abedi H, Asgari M, Kazemi Z, Saffari F, Nasiri M. Religious Care Patients and the barriers. J Teb Tazkieh. 2005;4(53):23-16. [Persian]

30- Matthews DA, Marlowe SM, Macnutt FS. Effects of intercessory prayer on patienationts with rheumatoid arthritis. South Med J. 2000;93(12):1177-86.

31- Rafiei GR. The role of prayer on physical and mental health. Qom Univ Med Sci J. 2011;5:66-73. [Persian] 32- Mohsenzadeh Ledari F, Hoseini Tabaghdehi M. Effect of Quran on the treatment of diseases: Literature review. Islam Health J. 2016;3(1):22-8. [Persian]

33- Vanderweele TJ. Religious communities and human flourishing. Curr Dir Psychol Sci. 2017;26(5):476-81.

34- Chida Y, Steptoe A, Powell LH. Religiosity/spirituality and mortality: A systematic quantitative review. Psychother Psychosom. 2009;78(2):81-90.

35. Hayward RD, Elliott M. Cross-national analysis of the influence of cultural norms and government restrictions on the relationship between religion and well-being. Rev Relig Res. 2014;56:23-43.

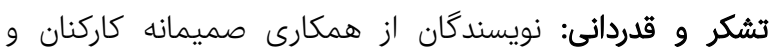

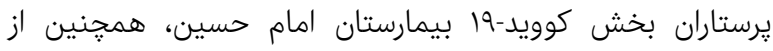

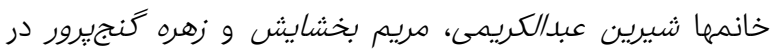

$$
\begin{aligned}
& \text { جمعآورى دادهها كمال تشكر و قدردانى را دارند. }
\end{aligned}
$$

1-Sohrabi C, Alsafi Z, O'Neill N, Khan M, Kerwan A, Al-Jabir $A$, et al. World health organization declares global emergency: A review of the 2019 novel coronavirus (COVID-19). Int J Surg. 2020;76:71-6.

2- Gorbalenya AE, Baker SC, Baric RS, De Groot RJ, Drosten C, Gulyaeva AA, et al. Severe acute respiratory syndromerelated Coronavirus-the species and its viruses, a statement of the Coronavirus study group. Biorxiv. 2020 Feb:1-15.

3- Heymann DL, Shindo N. COVID-19: What is next for public health. Lancet. 2020;395(10224):542-5.

4.Zu ZY, Jiang MD, Xu PP, Chen W, Ni QQ, Lu GM, et al. Coronavirus disease 2019 (COVID-19): A perspective from China. Radiology 2020;296(2):15-25.

5-Sun P, Qie S, Liu Z, Ren J, Li K, Xi J. Clinical characteristics of hospitalized patients with SARS-CoV-2 infection: A single arm meta-analysis. J Med Virol. 2020;92(6):612-7. 6- Joost Wiersinga W, Rhodes A, Cheng AC, Peacock SJ, Prescott HC. Pathophysiology, Transmission, Diagnosis, and Treatment of Coronavirus Disease 2019 (COVID-19)A Review. JAMA. 2020;324(8):782-93.

7- Wu YC, Chen CS, Chan YJ. Overview of the 2019 novel Coronavirus (2019-Ncov): The pathogen of severe specific contagious pneumonia (SSCP). J Chin Med Assoc. 2020;83(3):1

8- Rosa SGV, Santos WC. Clinical trials on drug repositioning for COVID-19 treatment. Rev Panam Salud Publica. 2020;44:40.

9- Tavakoli A, Vahdat K, Keshavarz M. Novel Coronavirus disease 2019 (COVID-19): An emerging infectious disease in the 21st century. Iran South Med J. 2020;22(6):432-50. [Persian]

10- United nations. Report of the world summit for social development: Copenhagen, 6-12 March 1995 [Report]. New York: United Nations; 1996. Report NO.:96IV8.

11- Pargament KI, Koenig HG, Perez LM. The many methods of religious coping: Development and initial validation of the RCOPE. J Clin Psychol. 2000;56(4):51943.

12- Koenig HG. Religion, spirituality, and health: The research and clinical implications. Psychiatry. 2012;2012:278730.

13- Bormann JE, Gifford AL, Shively M, Smith TL, Redwine L, Kelly A, et al. Effects of spiritual mantram repetition on HIV outcomes: A randomized controlled trial. J Behav Med. 2006;29(4):359-76.

14- Liao L. Spiritual care in medicine. JAMA. 2017;318(24):2495-6.

15- Syed IB. Spiritual medicine in the history of Islamic medicine. J Int Soc Hist Islam Med. 2003;2(4):45-9.

16- Ganguly S, Bakhshi S. Traditional and complementary medicine during COVID-19 pandemic. Phytother Res. 2020;34(12):3083-4.

17- Portella CFS, Ghelman R, Abdala CVM, Schveitzer MC. Evidence map on the contributions of traditional, complementary and integrative medicines for health care in times of COVID-19. Integr Med Res. 2020;9(3):100473 
تاثير افزودن مراقبت معنوى به درمانهاى معمول بر روند بهبودى بيماران بسترى مبتلا به كوويد-19: كارآزمايى بالينى تصادفى ابr

44- Kleinman EM, Liu RT. Prospective prediction of suicide in a nationally representative sample: Religious service attendance as a protective factor. Br J Psychiatry. 2014;204:262-6.

45- Li S, Okereke OI, Chang SC, Kawachi I, Vanderweele TJ. Religious service attendance and lower depression among women: A prospective cohort study. Ann Behav Med. 2016;50(6):876-84.

46- Vanderweele TJ, Li S, Tsai A, Kawachi I. Association between religious service attendance and lower suicide rates among US women. JAMA Psychiatry. 2016;73(8):845-51.

47- Boelens PA, Reeves RR, Replogle WH, Koenig HG. A randomized trial of the effect of prayer on depression and anxiety. Int J Psychiatry Med. 2009;39(4):377-92.

48- Tloczynski J, Fritzsch S. Intercessory prayer in psychological well-being: Using a multiple-baseline, across-subjects design. Psychol Rep. 2002;91(3 Pt 1):73141.

49- Anderson JW, Nunnelley PA. Private prayer associations with depression, anxiety and other health conditions: An analytical review of clinical studies. Postgrad Med. 2016;128(7):635-41.

50- Carvalho CC, De Cassia Lopes Chaves E, Iunes DH, Simao TP, Da Silva Marciano Grasselli C, Braga CG. Effectiveness of prayer in reducing anxiety in cancer patients. Rev Esc Enferm USP. 2014;48(4):683-9.

51- Carmody J, Reed G, Kristeller J, Merriam P. Mindfulness, spirituality, and health-related symptoms. J Psychosom Res. 2008;64(4):393-403.

52- Sharif Nia SH, Hojjati H, Nazari R, Qorbani M, Akhoondzade G. The effect of prayer on mental health of hemodialysis patients. Iran J Crit Care Nurs. 2012;5(1):29-34. [Persian]
36- Li S, Stamfer MJ, Williams DR, Vanderweele TJ. Association between religious service attendance and mortality among women. JAMA Intern Med. 2016;176(6):777-85.

37- Vanderweele TJ, Yu J, Cozier YC, Wise L, Argentieri MA, Rosenberg L, et al. Religious service attendance, prayer, religious coping, and religious-spiritual identity as predictors of all-cause mortality in the black women's health study. Am J Epidemiol. 2017;185(7):51522.

38- Byrd RC. Positive therapeutic effects of intercessory prayer in a coronary care unit population. South Med J. 1988;81(7):826-9.

39- Benson H, Dusek JA, Sherwood JB, Lam P, Bethea CF, Carpenter W, et al. Study of the therapeutic effects of intercessory prayer (STEP) in cardiac bypass patients: A multicenter randomised trial of uncertainty and certainty of receiving intercessory prayer. Am Heart J. 2006;151(4):934-42.

40- Masters KS, Spielmans GI, Goodson JT. Are there demonstrable effects of distant intercessory prayer? a meta-analytic review. Ann Behav Med. 2006;32(1):21-6. 41- Aviles JM, Whelan SE, Hernke DA, Williams BA, Kenny $\mathrm{KE}$, O'Fallon $\mathrm{WM}$, et al. Intercessory prayer and cardiovascular disease progression in a coronary care unit population: A randomized controlled trial. Mayo Clin Proc. 2001;76(12):1192-8.

42- Leibovici L. Effects of remote, retroactive intercessory prayer on outcomes in patients with bloodstream infection: Randomized controlled trial. BMJ. 2001;323(7327):1450-1.

43- Koenig HG. Research on religion, spirituality, and mental health: A review. Can J Psychiatry. 2009;54(5):283-91. 